\title{
V2G Transfer of Energy to Various Applications
}

\author{
Dr. G. Sree lakshmi ${ }^{1}, G$. Divya $^{2}, G$. Sravani $^{3}$ \\ ${ }^{1}$ Professor, CVR College of Engineering, Hyderabad, India \\ ${ }^{2}$ Assistant Professor, CVR College of Engineering, Hyderabad, India \\ ${ }^{3}$ Assistant Professor, CVR College of Engineering, Hyderabad, India
}

\begin{abstract}
In today's world, there is a need of verge of significantant transformation in Electrical Power System. The Vehicle-to-Gird (V2G) concept optimizes this transformation. The PEV typically has a higher capacity Energy Storage System (ESS). Each PEV stores approximately 5-40kWh of energy. This energy can be transferred to the Vehicle-to-Grid (V2G), Vehicle-to-Home (V2H) and Vehicle-to-Building (V2B) as most of the time the vehicle is kept in parking as idle. This paper presents the concept of V2G technology, their classifications, battery storages and types of batteries for V2G.
\end{abstract}

\section{Introduction}

Hybrid Electric Vehicle to Grid is a technology of bidirectional flow of electrical energy from vehicle to grid. The system which integrates the electric vehicle into the grid is called Vehicle to Grid system and its interesting feature is to store, sell, or to distribute power [1]-[6]. Hybrid electric vehicles are under development in the recent market by various manufacturers because it also reduces pollution level which is very much useful for future generation to live in healthy environment. In the developing market these vehicles helps in improving the transportation system and helps in reducing our dependence on consumption of petroleum and helps grid to overcome its problems during peak demand [7]-[12]. Because one properly designed vehicle can generate $10 \mathrm{~kW}$ of power which is equal to power used by 10 houses. PHEV main aim is to shift energy demand for the individual transportation sector from crude oil to electricity. PHEV rely mostly on a battery and on electric motor. Once the battery is discharged, it is again charged by plugging PHEV to power systems. From records it is noted that the average travelling time of a vehicle is about 2 to 4 hours only, rest of the time it is in the parking slot. So, when the vehicle is in parking the battery can be used as power storage and the existing battery power can be fed back into the grid if there is any deficit of power in grid [13]-[19].

In this paper, an electric utility grid-connected energy management strategy and the stages involved in PEVs to transfer energy to V2G are demonstrated. Typically, there are multiple designs that may be used in designing the hybrid electric vehicle as per the customer. To apply this concept, communication between Vehicle and grid is needed, unidirectional power flow is best option because it reduces hardware requirement, interconnection problem and degradation of battery cycles usage. In this paper we will start with basic concept of EHV, next we will study about batteries system, technical details of $\mathrm{V} 2 \mathrm{G}$, stages, applications, advantages, disadvantages, finally about the regulations and standards and its conflicts are explained. Fig.1 shows the transfer of energy from V2G, V2H and V2B. Also, Renewable energy generation is taking place. Fig. 2 shows the block diagram of power flow from G2V. It is expected more than 20 million of PEVs will be on road as on 2020.

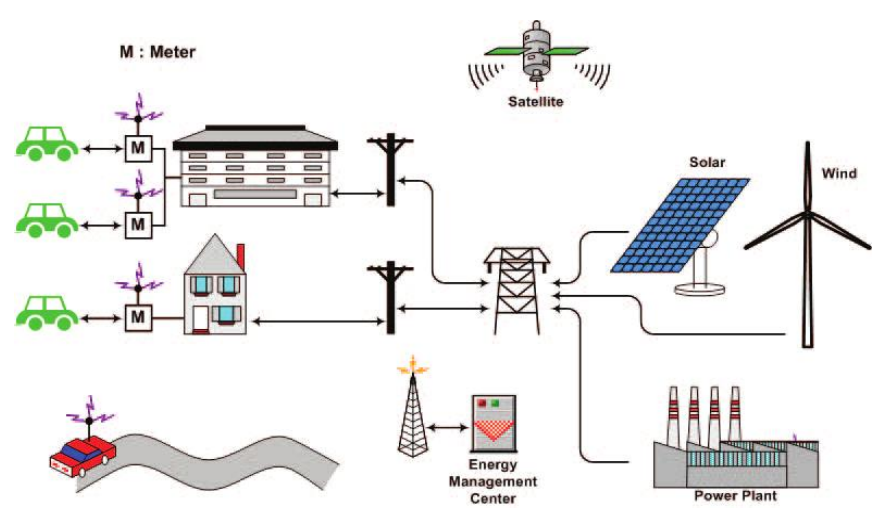

Fig.1 Overview of V2G, V2H and V2B with Renewable energy systems

\footnotetext{
* Corresponding author: Dr. G. Sree lakshmi
} 


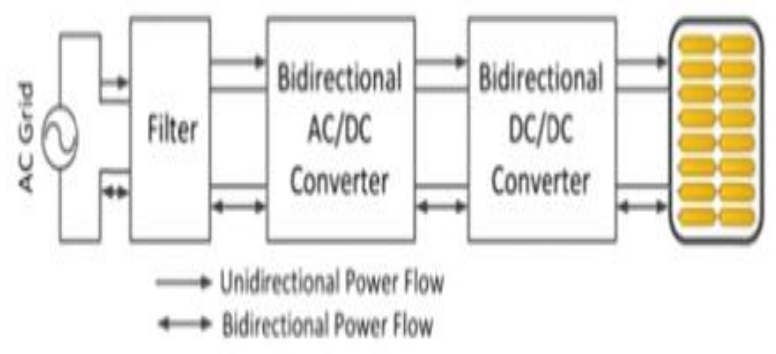

Fig.2 Block Diagram of power flow from G2V

\section{Types of Batteries for V2G}

The durable, safe, high energy and cost effective batteries have come from lead-acid batteries, batteries nickel-metal hydride (NiMH) to lithium-ion (Li-ion) batteries. Battery cost is the responsible of $20-40 \%$ of PEV price. The energy density of battery has been improved from $60 \mathrm{Wh} / \mathrm{L}$ to $150 \mathrm{Wh} / \mathrm{L}$. Also, the cost of the battery is going down with the improvement in the battery technologies. The present market is using Li-ion batteries as they have long range, higher density, lower cost and non-toxic behavior. They require less time to get charged. Nisan Leaf, Mitsubishi, Tesla Model and Chevrolet Volt are using Li-ion battery for energy storage system. Fig. 3 shows the history of batteries for PEVs.

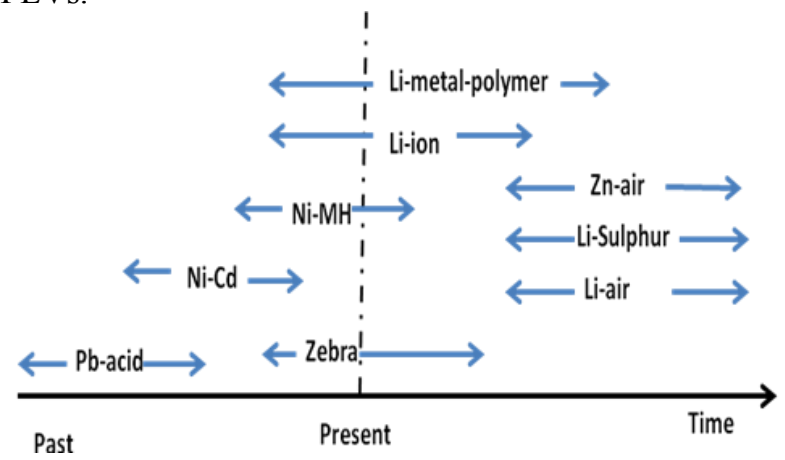

Fig.3 History of Batteries for PEV

Battery degradation is very important if the vehicle is used to travel as well as to transfer energy. The aging of batteries are due to cycling and calendar aging. For medium-long term applications Li-ion batteries are used. Lithium Sulphur (Li-S) has high energy density of $300 \mathrm{Wh} / \mathrm{L}$ but low battery life. Graphene is one which can solve this problem to some extent. Another promising and cheap technology is Lithium-air batteries which can give $1500 \mathrm{Wh} / \mathrm{L}$ energy density but needed further research to address several technical challenges.

\section{V2G Classifications Based on Batteries Used}

\subsection{Fuel Cell Vehicles}

It uses fossils fuels, bio fuels and hydrogen fuels to generate power using generator which is inbuilt in vehicle during high demand times.

\subsection{Rechargable Batteries}

These batteries store power during low peak hours that is during night and deliver power to grid during high peak hours.

\subsection{Small Renewable Energy Power Stations}

Solar vehicle can store power during sun hour and deliver power to grid when battery is full or during high demand period.

\section{PEVs classisfications based on Energy Transfer}

The integration of PEVs is very important for electric grid operation. The integration has to be done based on charging and discharging of PEVs by using various strategies and control methods. The various applications of PEVS are V2H, V2B and V2G.

\subsection{Vehicle to Home (V2H)}

The main objective of Vehicle to Home (V2H) is to store energy from local distributed energy resources such as solar energy and wind energy and deliver it to home loads. This will reduce energy bills, improve efficiency and can provide backup power. Other components that can be present in a V2H system are smart loads, other static storage systems and combined heat and power generators (CHP) such as micro gasturbines. This can be integrated into smart home concept. V2H is composed of at least one $\mathrm{PEH}$, a bidirectional charger, home loads, small-scale distributed generation, a smart meter, home grid and home energy management system.

The other components are smart loads, static storage systems and combined heat and power generators such as micro gas-turbines. Smart metering plays a very important role in $\mathrm{V} 2 \mathrm{H}$ concept. It will register data about system consumption and also provides interface to send or receive information from utilities. This concept can be integrated into larger control systems to reduce burden the distribution electric grids. Also, the possibility that PEV user receiving the stop charging request from utilities in their smart phones are made available. Fig. 4 shows the Vehicle-to-Home technology energy transfer which has a smart metering in it. Which effectively transfer energy from Vehicle to House during non travelling hours of the vehicles. 


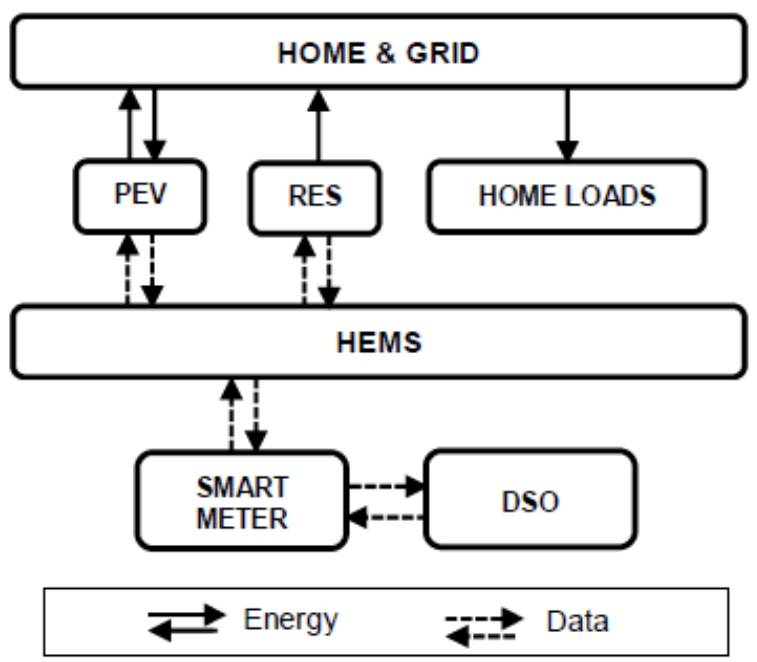

Fig.4 Vehicle-to-Home Technology

\subsection{Vehicle to Building (V2B)}

Vehicle-to-Building technology is attracting many people. It is an intermediate step between $\mathrm{V} 2 \mathrm{H}$ and $\mathrm{V} 2 \mathrm{G}$ but provides important advantages for PEVs and Building Owners. Both of them can achieve savings in energy bills as the arriving and departure timings of the workers are known. They can help to transfer energy for hospitals, hotels, universities, office buildings, shopping centers and especially during critical loads. IT consists of set of PEVs, distributed energy generators, critical loads, static storage and Building Energy Management control system. BEMS execute optimum algorithms to send the calculated set-point to different subsystems including the PEVs under its control.

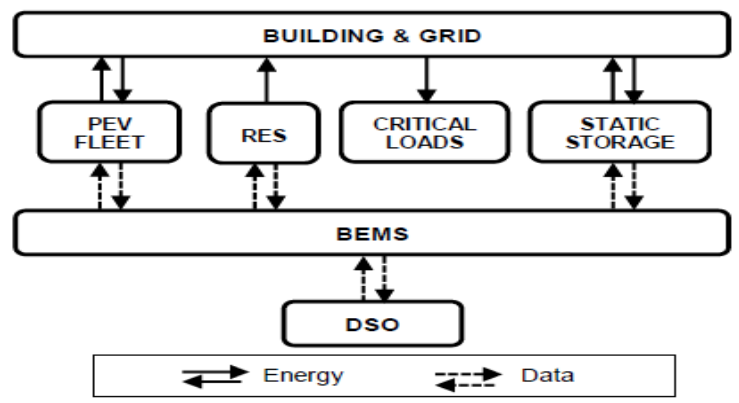

Fig.5 Vehicle to Building Technology

\subsection{Vehicle to Grid (V2G)}

Vehicle-to-Grid technology was introduced in the year 1997 by Willet Kempton and Steven E. Letendre. This concept explores the possibilities of using PEVs as distributed energy generators. It provides services like spinning and regulation services, peak power and even voltage regulation to distribution system operators. PEVs can provide distributed storage capacity for renewable energy sources. The batteries have very fast response and well suited for primary and secondary frequency regulation. There are two control architectures in V2G systems, centralized and decentralized. In centralized systems the charging and discharging decision in every PEV is taken by aggregator. Whereas, in decentralized controls the decision corresponds on every PEV of the system.

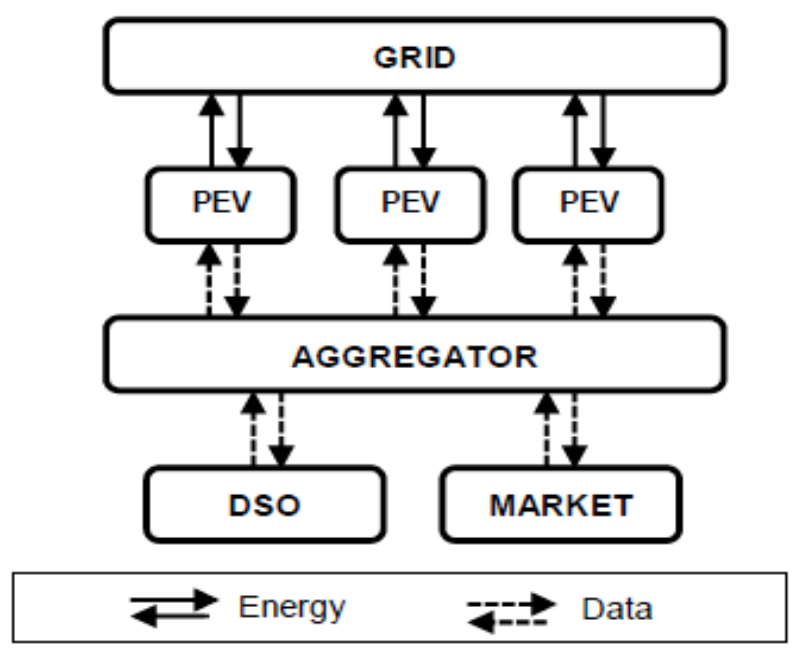

Fig.6 Vehicle to Grid Technology

\section{Vehicle Energy Storage System DESIGN}

The Energy Storage Systems for PEVs is electromechanical in nature. They consist of cells, modules, packaging, a thermal management system and a battery management system. The battery pack is made up of thousands of cells that are assembled into modules which are connected in series to increase the voltage. the most common type of cell packaging are cylindrical, prismatic and pouch cells. The BMS is the control center for ESS. The BMS keep track of the state of charge of ESS and control the current flow from inside and outside of the vehicle. The TMS ensures the temperature range of ESS. There is a communication path between BMS and the pack and between BMS and TMS.

\subsection{Renewable energy Integration with V2G}

As the high storage capacity batteries are costly the usage of the renewable sources is not adopted quickly. Moreover the power produced by the renewable energy sources is not constant all the time, so it is becoming difficult during peak load hours from 4 to $9 \mathrm{pm}$ to get the power without fluctuations. For example if wind power is taken, depending on the wind capacity the grid may be over wheeled or face shortage of power. So if PHV are connected to the grid during these peak hours, it can add advantage to the grid to overcome the peak demand. Integrating this EHV and renewable energy resources can help increasing the use of PHV.

\subsection{Vehicle to Grid Communication:}

The communication path should be a bi-directional. It should be common protocol, reliable, short time delay. There are multiple series connected stages in communication process, the stages is shown in block diagram.

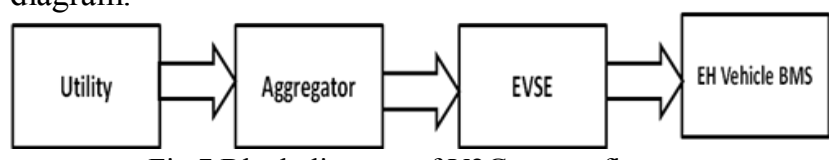

Fig.7 Block diagram of V2G power flow 
V2G technology should have a software which helps the vehicle owner to set time for charging, give information about tariff of power, preferences and also should be able to manage thousands of other vehicles on the grid leading to smart grid. This leads to more synchronizing grid and integrating renewable resources as well. The notification of availability of renewable resources also should be given to consumers so that consumers will not connect their vehicles to grid.

Aggregator: It is the mediator between operator and Plug-in electric vehicle which also participate in spinning. Aggregator also gives information of market rates.

EVSE : Electric vehicle supply equipment locks charge cable to provide additional saftey. Tariff selected by the EV is sent to EVSE, with given signal switching process takes placedpending on price of electricity on grid.

BMS : Battery managemnet system controls the rechargable battery by protecting it from voltage changes, temperature e.t.c.

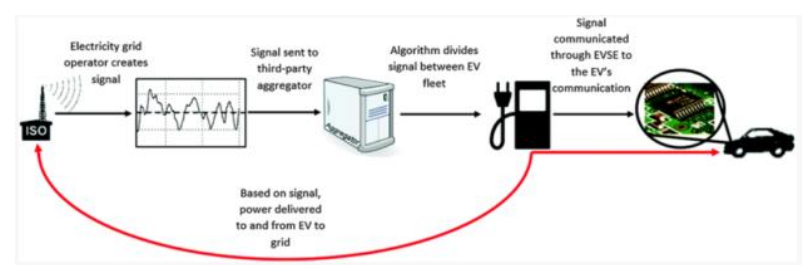

Fig :7.1 V2G communication technology

\subsection{Major Components of Vehicle to Grid}

$>$ Energy resources like renewable or nonrenewable resources and electric utility

$>$ Independent system operator for monitoring the system and aggregator

$>$ Charging point infrastructure and location for battery charging

$>$ Unidirectional communication electric flow between PEV and aggregator(when large no of EHV vehicles are connected aggregator increases its battery size to the point it has sufficient impact) for power transmission from grid to vehicle and vice versa.

$>$ Intelligent metering control system for identifying the capacity available

$>$ PEV with battery charger and management

\section{Charging Points for PEVs}

The main divisions of charging points are based on speed of charging. They are divided as

1. Rapid chargers

2. Fast chargers

3. Slow chargers

Rapid chargers: These are again divided into 3 types

1. AC charging: In first type of charging points, normal type of charging points which is used in houses and work place. The rating of this type of charging point is $16 \mathrm{~A}$ and $110 \mathrm{~V}$ to $120 \mathrm{~V}$ AC charging.

2. Where as in second type of charging points the maximum current is $19.2 \mathrm{KW}$ and 220 to $240 \mathrm{~V}$
AC. This type helps in fast charging and discharging of PHV.

3. DC charging points: These can be used in public and commercial places and these are similar to gas stations.

These types of chargers allow us to charge $80 \%$ of battery in 30 minutes. So the vehicle can run up to 80 to 100 miles.

Fast chargers: These types of chargers can charge PHV vehicle fully in 3 to 4 hours. The power output of these devices is around 7 to $22 \mathrm{~kW}$.

Slow chargers: This type of chargers time is from 2 to 4 hours and its power output is only $3 \mathrm{~kW}$.

\subsection{Charging Points at Home}

It is the easiest way to charge a PHEV at home and it is the cheapest way. Government is also providing subsidies for this. The output power is about 3 to $7 \mathrm{~kW}$. Even car manufacturers are also making deals with charger companies.

\subsection{Charging points at Work place and commercial places}

Many companies are planning to install sockets to plugging-in EV as most of the time the vehicle will be stationary at this place. In commercial places these charger can attract the customers to park their vehicles. In these places total output range is from 7 to $22 \mathrm{~kW}$.

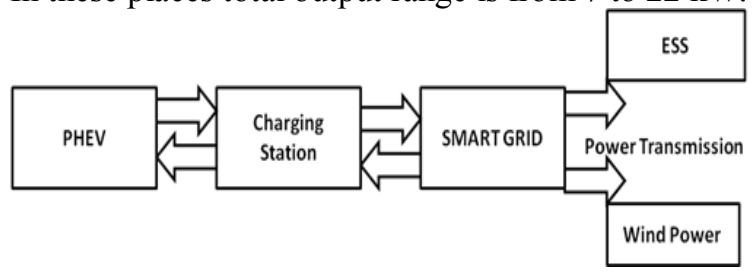

Fig.8 Bi-directional transfer of power from V2G

\section{Advantages, Disadvantages \& Standards}

\subsection{Applications of V2G}

1. Power is provided to help balance the load by valley filling, peak shaving (that is charging during the low peak hours and discharging during high peak hours into the grid). This is nothing but peak leveling.

2. $\mathrm{V} 2 \mathrm{G}$ can also provide peak power for 3-4 hours a day. [Peak power is nothing but giving the supply during high demand time]. This helps in reducing gap between the energy demands in power system, also reduces transmission loses, investment in transmission loses, mainly the stress in power system.

3. $\mathrm{V} 2 \mathrm{G}$ also can act as spinning reserve which means it can provide power within $10 \mathrm{~min}$, when operator demands for power. But this sudden requirement of power should pay additional amount to energy delivering device. The price is divided as[a] Capacity price: Price for responding in a minute notice, [b] Energy price: Price for actual energy output given to 
grid. Electric vehicle can behave as spinning reserve only for 3 to 4 hours a day.

\subsection{Advantages of V2G}

1. Electric vehicles are cheaper source of transportation for consumers as electricity price is lower than the fuel prices.

2. It provides additional revenue to the owners of the vehicle.

3. Electric utility system also have advantages because it will get power from the vehicle during peak period times

4. It reduces pollution by reducing the use of renewable sources.

5. The environment for $\mathrm{V} 2 \mathrm{G}$ can be houses, parking lots, employers working place and publicity available charging stations.

\subsection{Disadvantages of V2G}

1. $\mathrm{V} 2 \mathrm{G}$ is not a cheap source when compared to large power plant power generation.

2. Large scale use of these vehicles may lead to technical problems.

3. Compatibilities difficulties may arise when small scale generations are integrated into large power generating units.

\subsection{Standards and Regulations for V2G}

Identification of standards, regulations, codes for making $\mathrm{V} 2 \mathrm{G}$ to be used worldwide. This project is basically divided into 3 stages

1. Stage 1: Modes of operation and functionalities of $\mathrm{V} 2 \mathrm{G}$

2. Stage 2: models, codes, regulations which are in the market as of today

3. Stage 3:Common set of regulations which are to be designed

The main success of this technology is achieved only when the electric utilities and the judiciary should share information to the agencies so that quick adoption of the technology can take place and fix the standards national wide. These standards of National Institute of Standards and Technology, Institute of Electrical and Electronic Engineering society, Automotive engineering proceedings should be followed by the local authorities to implement V2G.

\section{Conclusion}

In this paper, the concept of V2G, their classifications, batteries used, battery storage system, charging points, various V2G technologies, advantages, disadvantages and standards are clearly stated. Also, how renewable energy sources are used for PEVs has studied. It has observed that, usage of V2G reduces the use of inefficient investment in conventional generation and promotes use of renewable sources. V2G also helps grid to select best options from available renewable sources in fixing tariff at low rates. But with this cost of renewable sources increases because storage of energy is needed. As the renewable sources are not obtained all the time in a day.

\section{References}

1. J. Krumm, "How People Use Their Vehicles: Statistics from the 2009 National Household Travel Survey," Apr. 2012.

2. W. Kempton and J. Tomić, "Vehicle-to-grid power implementation: From stabilizing the grid to supporting large-scale renewable energy," J. Power Sources, vol. 144, no. 1, pp. 280-294, Jun. 2005.

3. E. V. Landscape, "Global EV outlook for 2020," 2013. [Online]. Available: http://www.iea.org/publications/globalevoutlook_20 13.pdf. [4] "Monthly Plug-In Sales in US." [Online]. Available: http://insideevs.com/monthly-plug-insales-scorecard/.

4. B. K. Sovacool and R. F. Hirsh, "Beyond batteries: An examination of the benefits and barriers to plugin hybrid electric vehicles (PHEVs) and a vehicle-togrid (V2G) transition," Energy Policy, vol. 37, no. 3, pp. 1095-1103, Mar. 2009.

5. J. Tomić and W. Kempton, "Using fleets of electricdrive vehicles for grid support," J. Power Sources, vol. 168, no. 2, pp. 459-468, Jun. 2007.

6. B. Lunz, Z. Yan, J. B. Gerschler, and D. U. Sauer, "Influence of plug-in hybrid electric vehicle charging strategies on charging and battery degradation costs," Energy Policy, vol. 46, pp. 511519, Jul. 2012.

7. J. D. K. Bishop, C. J. Axon, D. Bonilla, M. Tran, D. Banister, and M. D. McCulloch, "Evaluating the impact of $\mathrm{V} 2 \mathrm{G}$ services on the degradation of batteries in PHEV and EV," Appl. Energy, vol. 111, pp. 206-218, Nov. 2013.

8. M.-K. Song, Y. Zhang, and E. J. Cairns, "A longlife, high-rate lithium/sulfur cell: a multifaceted approach to enhancing cell performance.," Nano Lett., vol. 13, no. 12, pp. 5891-9, Jan. 2013.

9. X. Feng, M.-K. Song, W. C. Stolte, D. Gardenghi, D. Zhang, X. Sun, J. Zhu, E. J. Cairns, and J. Guo, "Understanding the degradation mechanism of rechargeable lithium/sulfur cells: a comprehensive study of the sulfur-graphene oxide cathode after discharge-charge cycling.," Phys. Chem. Chem. Phys., vol. 16, no. 32, pp. 16931-40, Aug. 2014.

10. K. G. Gallagher, S. Goebel, T. Greszler, M. Mathias, W. Oelerich, D. Eroglu, and V. Srinivasan, "Quantifying the promise of lithium-air batteries for electric vehicles," Energy Environ. Sci., vol. 7, no. 5, p. 1555, 2014.

11. D. P. Tuttle, R. L. Fares, R. Baldick, and M. E. Webber, "Plug-In Vehicle to Home (V2H) duration and power output capability," 2013 IEEE Transp. Electrif. Conf. Expo, pp. 1-7, Jun. 2013.

12. C. Liu, K. T. Chau, D. Wu, and S. Gao, "Opportunities and Challenges of Vehicle-to-Home, Vehicle-to-Vehicle, and Vehicle-to-Grid 
Technologies," Proc. IEEE, vol. 101, no. 11, pp. 2409-2427, Nov. 2013.

13. F. Lambert, "Norway is reaching tipping point for electric vehicles as market share reaches record breaking 37\%", Electrek, 2017. [Online].

14. "Environmentally Sustainable Transportation Systems - Government Relations - SAE International", Sae.org,2017.

15. "Global ev outlook: Understanding the electric vehicle landscape to 2020", www.iea.org, 2017.

16. K. CZECHOWSKI, "Assessment of Profitability of Electric Vehicle-to-Grid Considering Battery", Graduate, KTH Royal Institute of Technology, 2015.

17. W. Kempton, and J. Tomic, Jun. 2005, "Vehicle-togrid power fundamentals: Calculating capacity and net revenue", J. Power Sources, vol. 144, 268-279

18. S. Shao, M. Pipattanasomporn, and S. Rahman, "Grid integration of electric vehicles and demand response with customer choice," IEEE Trans. Smart Grid, vol. 3, no. 1, pp. 543-550, Mar. 2012

19. M. Pipattanasomporn, M. Kuzlu, and S. Rahman, "An algorithm for intelligent home energy management and demand response analysis," IEEE Trans. Smart Grid, vol. 3, no. 4, pp. 2166-2173, Dec. 2012. 